\title{
The Brain Microvascular Endothelium Supports T Cell Proliferation and Has Potential for Alloantigen Presentation
}

\author{
Julie Wheway $^{1 *}$, Stephanie Obeid ${ }^{1}$, Pierre-Olivier Couraud ${ }^{2,3,4}$, Valery Combes ${ }^{1}$, Georges E. R. Grau ${ }^{1}$ \\ 1 Discipline of Pathology, Sydney Medical School, University of Sydney, Camperdown, New South Wales, Australia, 2 Unité 1016, Institut National de la Santé et de la \\ Recherche Médicale, Institut Cochin, Paris, France, 3 Unité Mixte de Recherche 8104, Centre National de la Recherche Scientifique, Paris, France, 4 Université Paris \\ Descartes, Paris, France
}

\begin{abstract}
Endothelial cells (EC) form the inner lining of blood vessels and are positioned between circulating lymphocytes and tissues. Hypotheses have formed that EC may act as antigen presenting cells based on the intimate interactions with $T$ cells, which are seen in diseases like multiple sclerosis, cerebral malaria (CM) and viral neuropathologies. Here, we investigated how human brain microvascular EC (HBEC) interact with and support the proliferation of T cells. We found HBEC to express MHC II, CD40 and ICOSL, key molecules for antigen presentation and co-stimulation and to take up fluorescently labeled antigens via macropinocytosis. In co-cultures, we showed that HBEC support and promote the proliferation of CD4 ${ }^{+}$and CD8 ${ }^{+} \mathrm{T}$ cells, which both are key in CM pathogenesis, particularly following T cell receptor activation and co-stimulation. Our findings provide novel evidence that HBEC can trigger $T$ cell activation, thereby providing a novel mechanism for neuroimmunological complications of infectious diseases.
\end{abstract}

Citation: Wheway J, Obeid S, Couraud P-O, Combes V, Grau GER (2013) The Brain Microvascular Endothelium Supports T Cell Proliferation and Has Potential for Alloantigen Presentation. PLoS ONE 8(1): e52586. doi:10.1371/journal.pone.0052586

Editor: Christine Bourgeois, INSERM, France

Received September 3, 2012; Accepted November 19, 2012; Published January 8, 2013

Copyright: ( 2013 Wheway et al. This is an open-access article distributed under the terms of the Creative Commons Attribution License, which permits unrestricted use, distribution, and reproduction in any medium, provided the original author and source are credited.

Funding: The study was funded by the National Health and Medical Research Council of Australia (http://www.nhmrc.gov.au/) project grants 1009914 and 571014 to VC and GEG; 1028241 to JW, VC and GEG; and 1022368 to GEG; fellowship 571397 to JW. Support was also provided through Rebecca L. Cooper Foundation equipment grants (http://www.cooperfoundation.org.au/). The funders had no role in study design, data collection and analysis, decision to publish, or preparation of the manuscript.

Competing Interests: Co-author Dr Valery Combes is a PLOS ONE Editorial Board member. This does not alter the authors' adherence to all the PLOS ONE policies on sharing data and materials.

*E-mail: julie.wheway@sydney.edu.au

\section{Introduction}

The induction of adaptive cellular immunity is a function of professional antigen presenting cells (APCs) such as dendritic cells, which provide signal 1 (peptide-major histocompatibility complex $(\mathrm{MHC})$ ), signal 2 (co-stimulatory molecules), and signal 3 (instructive cytokines) to naive $\mathrm{T}$ lymphocytes upon antigen encounter [1].

Endothelial cells (EC) form the inner lining of blood vessels and are positioned between circulating lymphocytes and peripheral tissues. As such, EC are the first cells with which T cells come into direct contact in the circulation. The hypothesis that EG may be able to act as APG is based upon the intimate interactions between $\mathrm{EC}$ in microvessels and $\mathrm{T}$ cells during transendothelial migration to lymph nodes or peripheral tissues. That is, EC may acquire antigenic proteins and present them on MHC class I and II molecules at their apical surface. The vascular EC that separate the blood stream from the brain parenchyma is referred to as the blood brain barrier (BBB). The BBB provides both anatomical and physiological protection for the central nervous system, regulating the entry of many substances and blood borne cells into the nervous tissue. There is increasing evidence of interactions between $\mathrm{T}$ cells and brain endothelium in diseases such as multiple sclerosis, cerebral malaria $(\mathrm{CM})$ and viral neuropathologies. Of particular note, the diameter of microvessels, where the pathology is seen during CM, is smaller than the size of activated lymphocytes; therefore the latter physically "brush" the EC surface and can thus interact very closely. Additionally, during CM, both T cells and monocytes are arrested in brain microvessels [2] and we recently demonstrated that brain EC can display antigens from infected erythrocytes on their surface, thereby possibly initiating immune responses [3].

MHC expression, which is the primary requirement for APC activity has been demonstrated on EC with both MHC I and II upregulated following cytokine treatment [4-6]. Moreover, EC may also qualify as APCs due to the secretion of cytokines, particularly GM-CSF $[7,8]$. Some studies using MHC matched donors supports the model that cultured human EC are able to present antigen and thus re-activate primed $\mathrm{CD}^{+} \mathrm{T}$ cells [9-11]. However, EC are specifically able to re-stimulate $\mathrm{T}$ cells, but not to prime naïve $\mathrm{T}$ cells, which is a hallmark of "professional" APCs such as dendritic cells [12-14]. Additional studies using co-cultures of MHC-mismatched $\mathrm{EC}$ and $\mathrm{T}$ cells resulted in the activation of both $\mathrm{CD} 4^{+}$and $\mathrm{CD}^{+} \mathrm{T}$ cells suggesting that EC are able to present alloantigens [15,16].

The body of evidence supporting the role of EC as APC (reviewed in [17]) led us to investigate the capacity of brain microvascular EG to act as APG and modulate $\mathrm{T}$ cell activation and proliferation. Here we confirm and expand on previous data [18] and show that immortalised human brain microvascular hCMEC/D3 endothelial cells (HBEG) express MHC II and the 
co-stimulatory molecules CD40 and ICOSL following cytokine stimulation. We also demonstrate that HBEC were able to take up fluorescently labeled antigens via macropinocytosis and clathrin coated pits. Moreover in our peripheral blood mononuclear cell (PBMC)/HBEC co-cultures, HBEG support and promote the proliferation of both $\mathrm{CD}^{+}$and $\mathrm{CD}^{+} \mathrm{T}$ cells suggesting that the brain endothelium is able to process and present antigens to allogeneic $\mathrm{T}$ cells. Finally, we were able to demonstrate that the interaction between $\mathrm{T}$ cells and HBEC occurs in a 2-way fashion as the expression of MHC II on HBEC was significantly increased following co-culture with PBMC. Combined, our data indicates that EC can act as semi-professional APC, which has important implications for the presentation of antigens to $\mathrm{T}$ cells, resulting in the activation of the effector $\mathrm{T}$ cell response in neuroinfectious diseases, particularly CM.

\section{Materials and Methods}

\section{Ethics Statement}

The blood samples used in this study are from anonymous donors from the Australian Red Cross Blood Bank. Protocol was approved by the University of Sydney Human Ethics Committee (Approval \#10218).

\section{Cells and cell culture}

Immortalised human brain microvascular hCMEC/D3 endothelial cells (HBEG) [18] were cultured in EBM-2 medium (Lonza CC-3156). Cells were grown on plates pre-coated with rat tail collagen type I (BD Biosciences). Cytokine activation of HBEC was performed by treating the cells with $10 \mathrm{ng} / \mathrm{ml} \mathrm{TNF}$ or $50 \mathrm{ng} /$ $\mathrm{ml}$ IFN $\gamma$ (Peprotech) for $18 \mathrm{~h}$.

\section{Human PBMC preparation}

PBMC were separated either from leukopacks or from heparinized venous blood by conventional Ficoll gradient and brought to $2 \times 10^{6} / \mathrm{ml}$ in complete medium. PBMC were frozen in $10 \%$ DMSO in FCS and stored in liquid nitrogen. PBMC were thawed and washed twice in cold medium before use in assays.

\section{T cell isolation and CFSE staining}

$\mathrm{CD}^{+}$and $\mathrm{CD}^{+} \mathrm{T}$ cells were isolated from freshly thawed PBMCs using an Easysep ${ }^{\circledR}$ (Stemcell Technologies) negative selection kit according to the manufacturer's instructions. For labeling both isolated T cells and whole PBMCs with Carboxyfluorescein succinimidyl ester (CFSE; Invitrogen), cells (at a density of $10^{7} \mathrm{cells} / \mathrm{ml}$ ) were incubated for $10 \mathrm{~min}$ at $37^{\circ} \mathrm{C}$ in $5 \mathrm{mM} \mathrm{CFSE}$ in serum free RPMI. The labelling reaction was stopped by the addition of serum. Cells were then washed 3 times prior to use. For the quantification of cell proliferation, cells were analysed by flow cytometry with a reduction in CFSE MFI indicative of cell division.

\section{Flow cytometry}

For multicolor flow cytometric analysis, HBEC were incubated in the presence of fluorochrome-conjugated mAbs against CD105 (SN6), CD106 (STA), CD80 (2D10.4), CD86 (IT2.2), CD40 (5C3), HLA-DR/MHC II (LN3) and CD275 (MIH12) (all from eBioscience), CD54 (5.6E; Beckman Coulter) and $\beta_{2}$-microglobulin/MHC I (TÜ99; BD Biosciences) as per manufacturer's instructions.

\section{Antigen uptake analysis}

The ability of HBEC to take up fluorescently labeled protein was assessed using flow cytometry after the cells were incubated with either $1 \mathrm{mg} / \mathrm{ml}$ Fluorescein isothiocyanate (FITC)-Ovalbumin (OVA) or Lucifer Yellow (Invitrogen) at $37^{\circ} \mathrm{C}$ for $45 \mathrm{~min}$ and washed three times with PBS. Results are expressed as the percentage increase in mean fluorescence intensity (MFI), which subtracts any fluorescence detected by nonspecific surface binding after incubation on ice. The percentage increase in MFI is calculated as follows; \% increase in MFI $=\left[\left(\right.\right.$ uptake at $\left.37^{\circ} \mathrm{C}\right) /$ (uptake at $\left.\left.4^{\circ} \mathrm{C}\right) \times 100\right]$. To selectively inhibit macropinocytosis and other actin-dependent mechanisms, HBEC were pre-incubated for $15 \mathrm{~min}$ at $37^{\circ} \mathrm{C}$ with cytochalasin $\mathrm{D}(\mathrm{CCD} ; 10 \mu \mathrm{M}$; Sigma).

\section{Conjugation assays}

The ability of HBEC to form long-lasting conjugates with $\mathrm{T}$ cells was assessed using an in vitro conjugation assay. Briefly, CD $4^{+}$ and $\mathrm{CD}^{+} \mathrm{T}$ cells were isolated from PBMC using EasySep ${ }^{\circledR}$. Isolated $\mathrm{T}$ cells and trypsinated HBEC were then labeled with the membrane-labeling agents, PKH26 (red) and PKH67 (green) respectively (Sigma). $1 \times 10^{5} \mathrm{~T}$ cells and $1 \times 10^{5} \mathrm{HBEC}$ were coincubated for $30 \mathrm{~min}$ at $37^{\circ} \mathrm{C}$ prior to flow cytometric analysis. Conjugates were deemed to be positive for both PKH26 and PKH27.

\section{In vitro $\mathrm{T}$ cell proliferation assays}

HBEC were cultured to confluence in 24 well tissue culture plates (Corning). Cells were either left under resting conditions or stimulated with a combination of $10 \mathrm{ng} / \mathrm{ml} \mathrm{TNF}$ and $50 \mathrm{ng} / \mathrm{ml}$ IFN $\gamma$ for $18 \mathrm{~h} .1 \times 10^{5}$ CFSE-labeled PBMCs were added per well with the following conditions; PBMC alone, $0.3 \mathrm{mg} / \mathrm{ml} \alpha \mathrm{CD} 3$ (eBioscience; Clone HIT3a) or $0.3 \mathrm{mg} / \mathrm{ml} \alpha \mathrm{CD} 3+1 \mathrm{mg} / \mathrm{ml}$ $\alpha$ CD28 (eBioscience; Clone CD28.2). The co-cultures were incubated for 6 days at $37^{\circ} \mathrm{C}$. After 6 days in culture the nonadherent cells were then collected for staining and flow cytometric analysis. Non-adherent cells were stained with PE conjugated antihuman CD4 (eBioscience; Clone OKT4) and PE-Cy5 anti-human CD8a (Biolegend; Clone HIT8a) prior to multi-colour flow cytometric analysis. $\mathrm{T}$ cell proliferation was then quantitated with the parameters set to a log scale. A forward scatter vs FL1 was used to gate on the PBMC population that was positive for CFSE. This gated population was then used to differentiate between $\mathrm{CD} 4^{+} \mathrm{T}$ cells and $\mathrm{CD}^{+} \mathrm{T}$ cells. CFSE histograms depict the number of events (y-axis) and the fluorescence intensity (x-axis) with proliferating cells displaying a progressive 2-fold loss in fluorescence intensity following cell division, indicative of proliferating cells. To determine whether cell contact is necessary for EC to support $\mathrm{T}$ cell proliferation, the use of transwells was employed. $1 \times 10^{5} \mathrm{PBMC} /$ well were placed in $0.4 \mu \mathrm{m}$ transwells (Costar) and co-culture with HBEC performed as outlined above.

\section{MHC II expression on HBEC following co-culture}

To assess the expression of MHC II on HBEC following coculture with PBMC, HBEG were removed by trypsinisation following $6 \mathrm{~d}$ of co-culture. HBEC were then stained with antihuman MHC II (HLA-DR; eBioscience). For flow cytometric analysis CFSE positive cells (PBMC) were excluded by gating to ensure MHC II analysis was conducted on HBEC only.

\section{Results}

HBEC express key molecules for antigen presentation and $\mathrm{T}$ cell activation

For this study we employed a particular line of immortalized human microvascular EC (HBEC; hCMEC/D3) that recapitulates many of the key characteristics of primary brain EC and thus has 
been validated as an excellent model of the BBB for in vitro studies [18-20].

A number of adhesion molecules known to be expressed by brain endothelium are involved, under inflammatory conditions, in the migration of activated leukocytes across the BBB. Flow cytometric analysis of HBEC cells not only confirmed the strong basal expression of ICAM-1, but also demonstrated a marked upregulation following stimulation with $\mathrm{TNF}$ and/or IFN $\gamma$ (Fig. 1). Endoglin (CD105), an EC marker predominantly expressed by proliferating EC was expressed at high levels basally, with no regulation in expression seen following pro-inflammatory cytokine stimulation (Fig. 1). Similarly, MHC I ( $\beta_{2}$-microglobulin) was expressed at high levels basally on HBEC with no increase observed following cytokine stimulation (Fig. 1). This is in contrast to previous results whereby MHC I expression has been shown to be upregulated by stimulation with IFN $\alpha,-\beta$ or $-\gamma$ [21]. Despite this, our results provide evidence that HBEC, like most cell types, possess the minimal requirement for antigen presentation to $\mathrm{CD}^{+}$ $\mathrm{T}$ cells. In contrast to MHC I, despite the low basal expression of MHC II on HBEC cells, its expression was greatly increased upon the addition of IFN $\gamma$ or $\mathrm{TNF}+\mathrm{IFN} \gamma$ (Fig. 1), highlighting a potential role for these cells in antigen presentation to $\mathrm{CD} 4^{+} \mathrm{T}$ cells. Previous analysis of MHC II on EC has proved difficult in vivo, with constitutive expression only detected in post-capillary venules [22]. Whilst the expression of the co-stimulatory molecules CD80/CD86 (B7-1/B7-2) was not detected on resting or cytokinestimulated HBEC cells, the co-stimulatory molecule, CD40 was detected following stimulation with IFN $\gamma$ or TNF+IFN $\gamma$ (Fig. 1), indicating that like MHC II the expression is regulated by IFN $\gamma$. Previously, CD40 has been demonstrated to be constitutively expressed on primary human brain ECs, with this expression being upregulated following cytokine stimulation [23]. The expression of this co-stimulatory molecule on brain EC provides key evidence for their potential role as APC as the binding of CD40L on helper T cells to CD40 activates 'APCs' to upregulate the expression of more co-stimulatory molecules, increase cytokine expression and promote $\mathrm{T}$ cell differentiation [24]. Finally, inducible co-stimulator ligand (ICOSL) expression was detected on HBEC following TNF stimulation (Fig. 1). ICOS and its ligand, ICOSL are members of the CD28 family of co-stimulators mediating effector T cell differentiation [25]. Previously, ICOSL has been detected not only basally on human umbilical vein ECs but also upregulated by cytokine stimulation $[25,26]$.

\section{HBEC take up antigens using macropinocytosis and clathrin-coated pits}

A recent study from our laboratory demonstrated that during malaria, the transfer of parasite antigens to ECs can take place [3], however, the precise mechanisms behind this remain unclear. The ability of our HBEC to take up soluble antigens was assessed in vitro using fluorescently labeled antigens in a classic antigen uptake experiment. The ability of HBEG to take up antigen via macropinocytosis and clathrin-coated pits was assessed using Lucifer yellow and FITC-OVA respectively. The amount of fluorescence incorporated into the cells at $37^{\circ} \mathrm{C}$ was measured by flow cytometry with nonspecific surface binding subtracted following incubation on ice. Interestingly, HBEC were able to take up FITC-OVA via clathrin-coated pits and macropinocytose Lucifer yellow (Fig. 2A, C respectively). To further prove that the uptake of antigen by HBEC was not an experimental artifact, a specific inhibitor of macropinocytosis and other actin-dependent mechanisms, cytochalasin D (CCD; $10 \mathrm{mM})$ was employed [27]. Indeed, following pre-incubation with CCD, both the uptake of FITC-OVA and Lucifer yellow was significantly inhibited (Fig. 2 $\mathrm{B}, \mathrm{D})$ indicating that HBEC have the capacity to take up soluble antigen in a similar manner as professional APC.

\section{HBEC support the proliferation of activated T cells}

As optimal T-cell activation and differentiation in vivo requires long-lasting $\mathrm{T}-\mathrm{APC}$ interaction, a classical in vitro conjugate forming assay was adapted to assess the ability of HBEC to form conjugates with T cells [28]. Red fluorescently labeled (PKH26) $\mathrm{CD}^{+}$or $\mathrm{CD}^{+} \mathrm{T}$ cells were incubated in suspension with green fluorescently labeled (PKH67) HBECs with the adherence between HBEC and $\mathrm{T}$ cells examined using flow cytometry.
ICAM-1

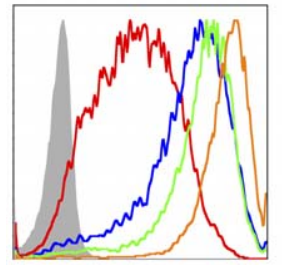

ICOSL

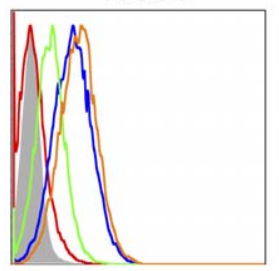

Endoglin

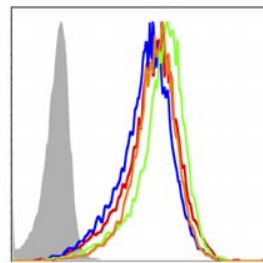

CD40

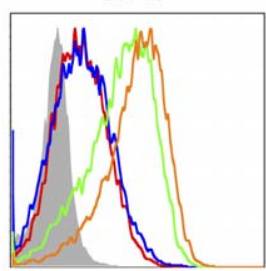

MHC I

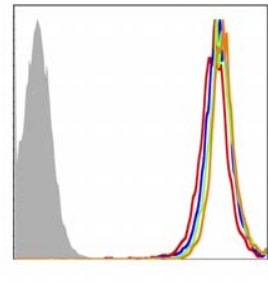

CD80

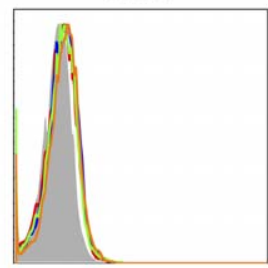

MHC II

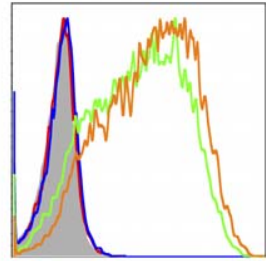

CD86

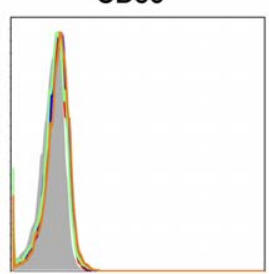

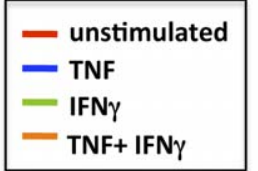

Figure 1. Expression of markers relevant to antigen presentation and $\mathbf{T}$ cell activation on HBEC. Histograms represent flow cytometry results from unstimulated and cytokine stimulated HBEC cells $18 \mathrm{~h}$ following stimulation. HBEC were stimulated with either $10 \mathrm{ng} / \mathrm{ml}$ TNF (blue line), $50 \mathrm{ng} / \mathrm{ml}$ IFNg (green line), or $10 \mathrm{ng} / \mathrm{ml} \mathrm{TNF}+50 \mathrm{ng} / \mathrm{ml} \mathrm{IFNg}$ (orange line) and compared to unstimulated cells (red line). Cells were stained with mAbs against CD54 (ICAM-1), Endoglin (CD105), MHC II (HLA-DR), ICOSL (CD275), CD40, CD80 and CD86 as per manufacturers instructions. Data are representative of four independent experiments. doi:10.1371/journal.pone.0052586.g001 
A

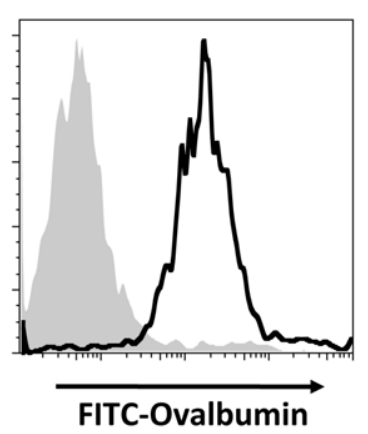

\begin{tabular}{|} 
Uptake at $4^{\circ} \mathrm{C}$ \\
- Uptake at $37^{\circ} \mathrm{C}$ \\
\hline
\end{tabular}

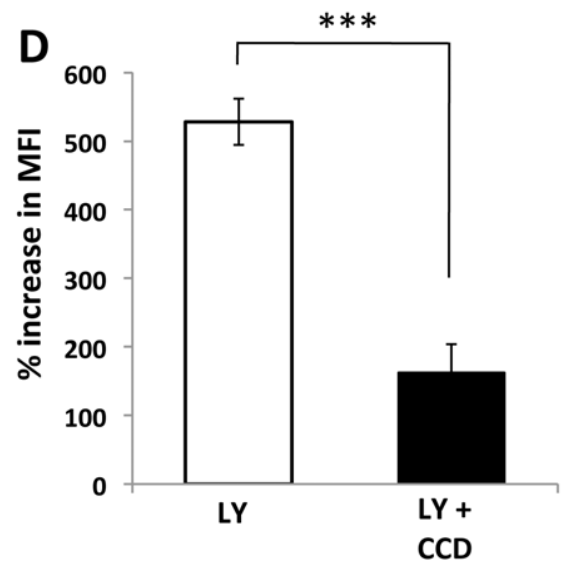

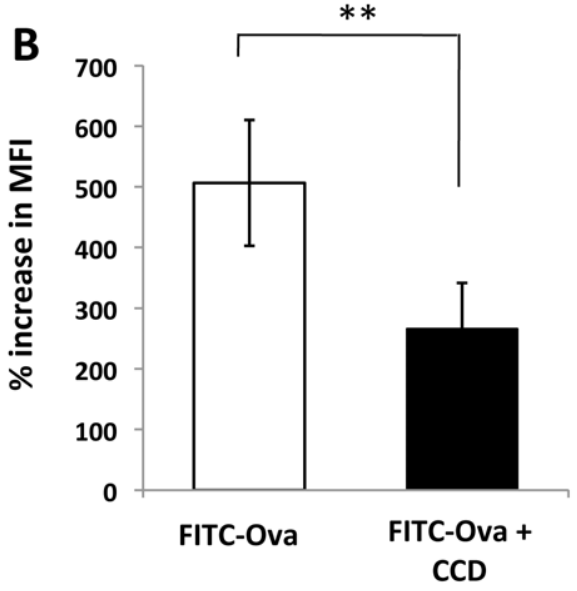

C

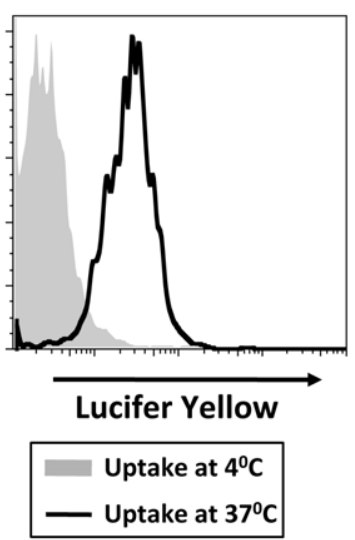

$\mathbf{E}$

$\mathrm{CD}^{+}$

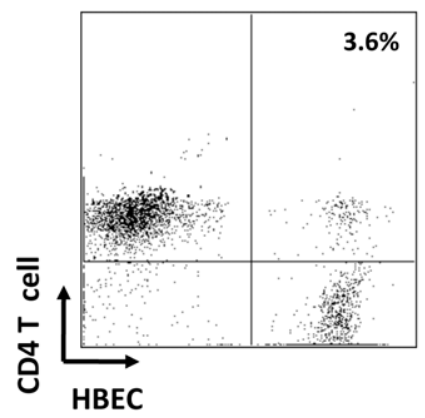

$\mathbf{F} \quad \mathrm{CD}^{+}$

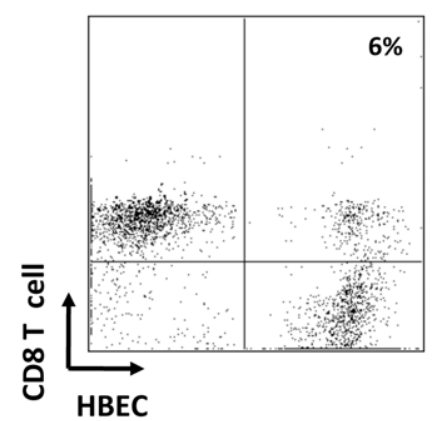

Figure 2. HBEC take up fluorescently labelled antigen via actin-dependent mechanisms and form conjugates with $\mathrm{T}$ cells. Flow cytometry histograms depicting level of uptake of FITC-OVA $(A)$ and Lucifer yellow $(C)$ by HBEC at $37^{\circ} \mathrm{C}$ (blue line) vs background uptake at $4^{\circ} \mathrm{C}$ (red line). Data are representative of three independent experiments. Inhibition of FITC-OVA $(B)$ and Lucifer yellow $(D)$ uptake by HBEC cells pre-incubated with $10 \mathrm{mM}$ Cytochalasin D (CCD). C, Flow cytometry histogram depicting level of uptake of Lucifer yellow by HBEC at $37^{\circ} \mathrm{C}$ (blue line) vs background uptake at $4^{\circ} \mathrm{C}$ (red line). Data are representative of three independent experiments Percentage increase in mean fluorescence intensity (MFI) is calculated as follows: (MFI following uptake at $37^{\circ} \mathrm{C} / \mathrm{MFI}$ following uptake at $\left.4^{\circ} \mathrm{C}\right) \times 100$. Data are pooled from three independent experiments $(n=3$ per experiment) and are expressed as mean $+/-$ SD. ${ }^{* *}$ and ${ }^{* * *}$ indicates statistically significant differences between control and CCD treatment as assessed by Student $t$ test $(p, 0.001, p<0.001$ respectively). Representative flow cytometry plots indicating the levels of conjugation between HBEC and $\mathrm{CD}^{+}(E)$ and $\mathrm{CD}^{+}$(F) cells. HBEC were labeled with PKH67 and isolated T cells labeled with PKH26 and equal numbers of cells were co-cultured for 30 min prior to flow cytometric analysis.

doi:10.1371/journal.pone.0052586.g002

Conjugates were determined to be cells positive for both PKH26 and PKH67. Interestingly, both $\mathrm{CD}^{+}$and $\mathrm{CD}^{+} \mathrm{T}$ cells form conjugates, i.e. cell doublets in suspension, with control (data not shown) and cytokine activated HBECs, as shown by flow cytometry (Fig. 2E, F respectively). There were higher percentages of $\mathrm{T}$ cell/HBEC conjugates seen when the HBEC were cytokine activated (3.6 vs $1.4 \%$ for $\mathrm{CD}^{+}$and 6.3 vs $2.1 \%$ for $\mathrm{CD}^{+}$).

After determining that HBEC were capable of binding to both $\mathrm{CD}^{+}$and $\mathrm{CD}^{+}{ }^{+} \mathrm{T}$ cells, the ability of HBEC to support $\mathrm{T}$ cell proliferation and present alloantigens was assessed by co-culturing CFSE-labelled donor PBMCs with a confluent monolayer of either resting or cytokine stimulated HBECs. In addition, the agonistic antibodies $\alpha \mathrm{CD} 3 / \alpha \mathrm{CD} 28$ were also added to the assay to mimic $\mathrm{T}$ cell receptor (TCR) stimulation and co-stimulation respectively [29]. Six days following co-culture the percentage of $\mathrm{CD}^{+}$and $\mathrm{CD}^{+} \mathrm{T}$ cells proliferating was determined by measuring the reduction in CFSE MFI (Fig. 3A). While the presence of soluble $\alpha \mathrm{CD} 3$ and $\alpha \mathrm{CD} 28$ resulted in a modest increase in proliferating
$\mathrm{CD}^{+}$cells, the only significant increase in proliferation was observed when the PBMC were co-cultured with TNF+IFN $\gamma$ activated HBEC and $\alpha$ CD3/ $\alpha$ CD28 (Fig. 3B), indicating that HBEC support the proliferation of $\mathrm{CD} 8{ }^{+} \mathrm{T}$ cells, however, the $\mathrm{CD} 8{ }^{+}$cells must also be activated via their TCR. Interestingly, $\mathrm{CD} 4^{+} \mathrm{T}$ cell proliferation was significantly increased in the presence of both resting and cytokine-stimulated HBEC (Fig. 3C), however, the $\mathrm{CD}^{+}$cells also must be stimulated via their TCR with $\alpha \mathrm{CD} 3$ or $\alpha \mathrm{CD} 3 / \alpha \mathrm{CD} 28$ to observe the HBEC-mediated support of proliferation. It is most likely that the modest increase in proliferation for both $\mathrm{CD}^{+}$and $\mathrm{CD}^{+} \mathrm{T}$ cells following $\alpha \mathrm{CD} 3$ stimulation is indicating that the cells were not stimulated using a solid phase activation, i.e. plate bound $\alpha \mathrm{CD} 3$.

Experiments using transwells have indicated that when the PBMC were physically separated from the HBEC monolayer during co-culture, the increase in proliferation over control samples were greatly reduced (Fig. S1). This was observed for both $\mathrm{CD}^{+}$and $\mathrm{CD}^{+} \mathrm{T}$ cells suggesting that direct interaction 

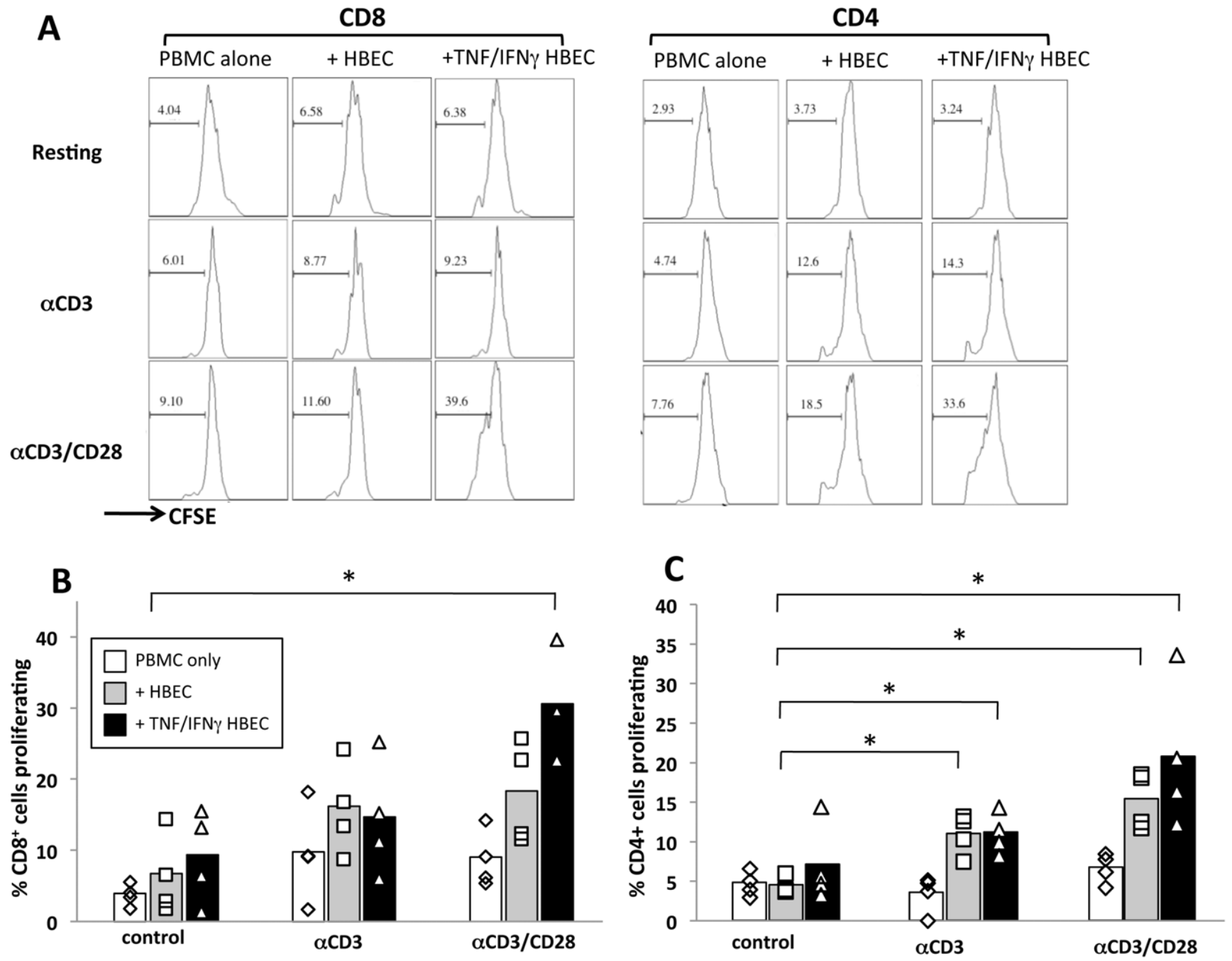

Figure 3. HBEC support the proliferation of CD4 ${ }^{+}$and $\mathrm{CD8}^{+} \mathbf{T}$ cells. $A_{1}$ CFSE histogram plots of gated $\mathrm{CD} 4^{+}$(left panel) and CD8 ${ }^{+}$(right panel) 6 days following the start of the co-culture of HBEC and donor PBMC. For co-culture $1 \times 10^{5}$ CFSE-labelled donor PBMC were co-cultured or not with a confluent monolayer of either resting or $10 \mathrm{ng} / \mathrm{ml} \mathrm{TNF}+50 \mathrm{ng} / \mathrm{ml} \mathrm{IFN} \gamma$ pre-stimulated HBEC cells. PBMC were either subjected to resting conditions or stimulation with $a \mathrm{CD} 3$ or $a \mathrm{CD} 3 / \mathrm{CD} 28 \mathrm{mAbs}$. Following 6 days of culture, cells were harvested and stained with CD4 and CD8 mAbs to identify proliferating cell populations. CFSE histograms depict the number of events ( $y$-axis) and the fluorescence intensity ( $x$-axis) with proliferating cells displaying a progressive 2 -fold loss in fluorescence intensity following cell division, indicative of proliferating cells. Histograms are representative of four independent experiments with the same donor. Graphical representation of the percentage of $\mathrm{CD} 4^{+}(B)$ and $C D 8^{+}(C)$ PBMC proliferating following 6 days of culture either alone (white bars) or in the presence of resting (grey bars) or cytokine stimulated (black bars) HBEC as outlined above. Data is pooled from four independent experiments with the same donor. * indicates statistically significant differences between control PBMC and respective co-culture conditions using a non-parametric Mann-Whitney test $(p<0.05)$.

doi:10.1371/journal.pone.0052586.g003

between HBEG and $\mathrm{T}$ cells is required for HBEC-mediated support of $\mathrm{T}$ cell proliferation.

\section{MHC expression on HBEC is upregulated following co- culture with allogeneic PBMC}

To determine whether the interaction between $\mathrm{T}$ cells and HBEC occurs in a two-way fashion, the expression of MHC II on the HBEC monolayer was determined following 6 days of coculture with PBMCs. A significant increase in MHC II-positive cells was observed when HBEC were co-cultured with $\alpha \mathrm{CD} 3$ or $\alpha \mathrm{CD} 3 / \alpha \mathrm{CD} 28$ stimulated PBMCs when compared to HBEC cells alone (Fig. 4A, B) indicating that the donor PBMC were able to modulate the MHC II expression on the HBEG themselves. These conjugates likely involve interactions of ICAM-1/LFA-1 and VCAM-1/VLA-4 on EC/T cells respectively in addition to interactions required for antigen presentation.

\section{Discussion}

In this study, we provide for the evidence that microvascular brain EC are able to act as APCs. Our analysis of MHC and costimulatory molecule expression on HBEC show for the first time that brain EC are endowed a "professional" costimulatory ligand of the B7 family, ICOSL. This in conjugation with the expression of MHC II and CD40 following IFN $\gamma$ stimulation supports the notion of the brain endothelium being able to present antigens to and co-stimulate $\mathrm{T}$ cells promoting effector $\mathrm{CD} 4^{+} \mathrm{T}$ cell responses. Additionally, with constitutively high expression of MHC I, 
A

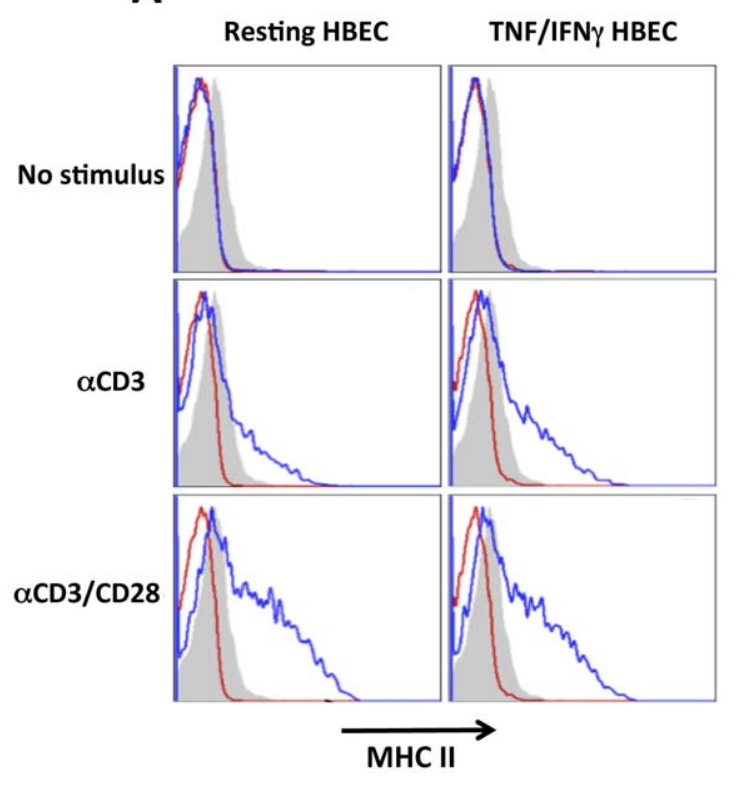

B

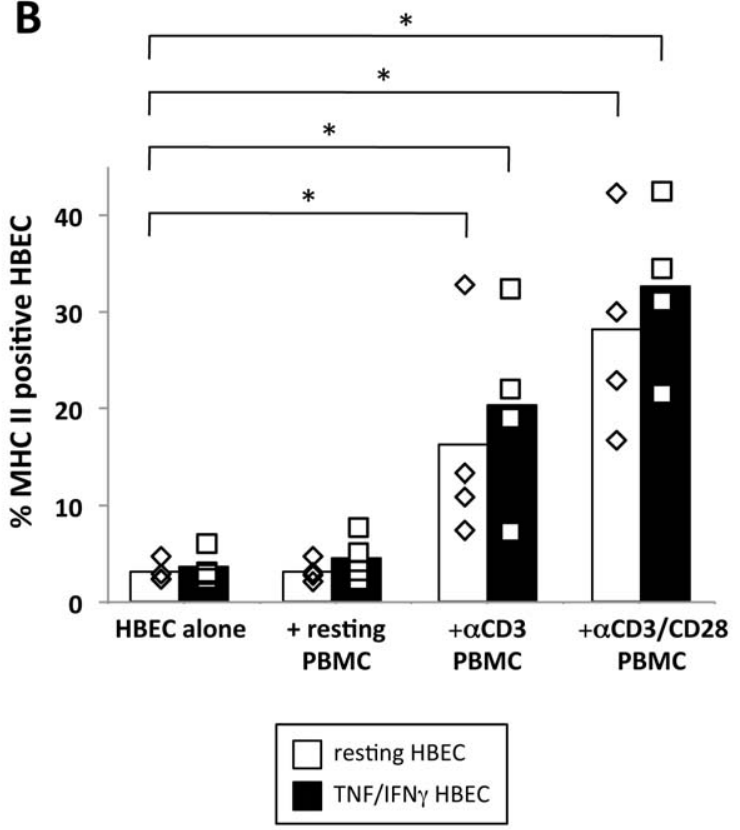

Figure 4. PBMC modulate MHC II expression on HBEC following co-culture. $A$, Histogram plots of HBEC depicting expression of MHC II (HLA-DR) 6 days following the start of the co-culture with donor PBMC. $1 \times 10^{5}$ CFSE-labelled donor PBMC were co-cultured with a confluent monolayer of either resting (left panels) or $10 \mathrm{ng} / \mathrm{ml} \mathrm{TNF}+50 \mathrm{ng} / \mathrm{ml} \mathrm{IFN} \gamma$ pre-stimulated (right panels) HBEC cells. PBMC were either subjected to resting conditions or stimulation with $a \mathrm{CD} 3$ or $a \mathrm{CD} 3 / \mathrm{CD} 28 \mathrm{mAbs}$ (top, middle lower panels respectively). Histograms are representative of four independent experiments with the same donor. B, Percentage of MHC II+ HBEC in resting (white bars) vs TNF/IFN $\gamma$ stimulated (black bars) HBEC. Data is pooled from four independent experiments with the same donor. ${ }^{*}$ indicates statistically significant differences between control HBEC and respective co-culture conditions using a non-parametric Mann-Whitney test $(p<0.05)$.

doi:10.1371/journal.pone.0052586.g004

HBEC, like most cell types, possess the minimal requirement for antigen presentation to $\mathrm{CD}^{+} \mathrm{T}$ cells.

Antigen uptake is the first step in antigen-presenting pathways, and pinocytosis is the major means by which cells sample soluble protein antigen. Here we show that HBEC are able to take up soluble antigen using both macropinocytosis and clathrin-coated pits as pathways for antigen uptake. Whilst liver sinusoidal EC have been demonstrated to be fully efficient APG in that they express co-stimulatory molecules [30], take up antigen via the mannose receptor [31] and are able to cross present exogenous antigen [32], no previous studies have been conducted on the ability of HBEC to take up and process antigens. The data presented here shows for the first time that HBEC are able to take up soluble antigen using actin-dependent mechanisms, in a manner similar to 'professional' APCs.

In the co-culture assays presented here, HBEC were able to support and promote the proliferation of TCR-stimulated CD $4^{+}$ and $\mathrm{CD}^{+} \mathrm{T}$ cells. In these assays, an MLR occurs and the $\mathrm{T}$ cells proliferate due to an MHC mismatch [33]. The demonstration of antigen-specific activation of human $\mathrm{T}$ cells by EC has previously been hampered by the requirement for MHC-matched EC and T cells. Some studies using MHC matched donors support the model that cultured human EC are able to present antigen and activated $\mathrm{CD}^{+} \mathrm{T}$ cells [9-11]. Moreover, mouse $\mathrm{T}$ cell clones or $\mathrm{T}$ cells from TCR-transgenic mice can be stimulated to proliferate in a peptide-antigen-specific manner by co-culture with MHCmatched ECs and the relevant protein antigen [14,34]. Additionally, as presented in this study with our HBEC line, co-cultures of
MHC-mismatched EC and T cells result in the activation of $\mathrm{CD} 4^{+}$ and $\mathrm{CD}^{+} \mathrm{T}$ cells demonstrating that $\mathrm{EC}$ are able to present alloantigens $[15,16]$. In this study we have used a widely accepted assay of allogenic $\mathrm{T}$ cell stimulation without well characterised antigens in order to prepare for future experiments that will involve defined malarial antigens. In this assay, the separation of HBEC and $\mathrm{T}$ cells resulted in reduced $\mathrm{T}$ cell proliferation, indicating the role of cell-cell contact in this phenomenon. The costimulatory molecules CD40 and ICOSL are likely to be mediating this effect. ICOSL, a B-7 co-stimulatory family member was upregulated on HBECs following cytokine stimulation. Moreover, ICOSL has been shown previously to be a major costimulator in Human umbilical vein EC-mediated $\mathrm{T}$ cell activation, particularly in the re-activation of effector/memory $\mathrm{T}$ cells [12,26]. Another co-stimulatory molecule, CD40, was constitutively expressed on HBEC and upregulated after IFN $\gamma$ stimulation (Fig. 1). CD40 regulates the adhesion of $\mathrm{CD} 4^{+} \mathrm{T}$ cells to brain endothelium via the interaction with its ligand, CD40L on $\mathrm{T}$ cells, suggesting a potential mechanism by which activated CD40L expressing T cells could enhance adhesion and migration of inflammatory cells across the BBB to sites of inflammation in the human central nervous system [23].

This increase in HBEC MHC II expression has relevance for CM pathogenesis as MHC II expression on isolated mouse brain EG has been associated with the genetic susceptibility to CM [35]. Moreover, more recently the HLA ligand, HLA-Cl along with its cognate natural killer $(\mathrm{NK})$ cell immunoglobulin-like receptor were shown to be significantly associated with the development of CM 
in humans [36]. EC, at least from lymph nodes, can be modulators of immune responses as they express multiple peripheral tissue antigens, independent of the autoimmune regulator, AIRE [37], and can even induce anergy [38]. This, together with our observation of malarial antigen transfer to brain EC surfaces [3], opens more possibilities for endothelial-mediated immunopathological mechanisms in CM. The findings described here are not only a major interest for understanding CM pathogenesis but also other neuroinfections involving disruption of endothelial cell barriers such as neurocysticercosis and toxoplasmosis [39,40].

In summary, we have shown that human brain endothelium cells express molecules important for $\mathrm{T}$ cell stimulation and activation including CD40, MHC II and ICOSL. They readily can take up fluorescently labeled antigens via clathrin-coated pits and macropinocytosis. Moreover, these cells are able to bind to and promote the proliferation of allogeneic $\mathrm{T}$ cells in vitro. Data presented here supports the hypothesis that HBEC are able to act as APC. This is particularly pertinent in neuroinfections such as $\mathrm{CM}$ where the diameter of microvessels is smaller than the size of lymphocytes; the lymphocytes are in constant physical contact with the EC surface. Additionally, in the brains of both mice and human with CM, leukocytes (monocytes and $\mathrm{T}$ cells) become arrested in brain microvessels [2] providing further means for intimate $\mathrm{EC} / \mathrm{T}$ cell interactions. It has long been established that $\mathrm{CM}$ is a $\mathrm{T}$ cell-dependent disease $[41,42]$, with both $\mathrm{CD}^{+}$and $\mathrm{CD}^{+} \mathrm{T}$ cells playing key roles in $\mathrm{CM}$ pathogenesis $[43,44]$. Moreover, this cell-cell contact plays an important role in brain endothelial activation [45], as assessed notably by a dramatic increase in plasma levels endothelial microparticles at the time of

\section{References}

1. Banchereau J, Steinman RM (1998) Dendritic cells and the control of immunity. Nature 392: 245-252.

2. Hunt NH, Grau GE (2003) Cytokines: accelerators and brakes in the pathogenesis of cerebral malaria. Trends Immunol 24: 491-499.

3. Jambou R, Combes V, Jambou MJ, Weksler BB, Couraud PO, et al. (2010) Plasmodium falciparum adhesion on human brain microvascular endothelial cells involves transmigration-like cup formation and induces opening of intercellular junctions. PLoS Pathog 6: e1001021.

4. Male DK, Pryce G, Hughes CG (1987) Antigen presentation in brain: MHC induction on brain endothelium and astrocytes compared. Immunology 60: 453-459.

5. Male D, Pryce G (1989) Induction of Ia molecules on brain endothelium is related to susceptibility to experimental allergic encephalomyelitis. J Neuroimmunol 21: 87-90.

6. Pober JS, Gimbrone MA Jr (1982) Expression of Ia-like antigens by human vascular endothelial cells is inducible in vitro: demonstration by monoclonal antibody binding and immunoprecipitation. Proc Natl Acad Sci U S A 79: $6641-6645$.

7. Verma S, Nakaoke R, Dohgu S, Banks WA (2006) Release of cytokines by brain endothelial cells: A polarized response to lipopolysaccharide. Brain Behav Immun 20: 449-455.

8. Lou J, Donati YR, Juillard P, Giroud C, Vesin C, et al. (1997) Platelets play an important role in TNF-induced microvascular endothelial cell pathology. Am J Pathol 151: 1397-1405.

9. Hirschberg $H$ (1981) Presentation of viral antigens by human vascular endothelial cells in vitro. Hum Immunol 2: 235-246.

10. Hirschberg H, Hirschberg T, Jaffe E, Thornsby E (1981) Antigen-presenting properties of human vascular endothelial cells: inhibition by anti-HLA-DR antisera. Scand J Immunol 14: 545-553.

11. Burger DR, Ford D, Vetto RM, Hamblin A, Goldstein A, et al. (1981) Endothelial cell presentation of antigen to human T cells. Hum Immunol 3: 209-230.

12. Khayyamian S, Hutloff A, Buchner K, Grafe M, Henn V, et al. (2002) ICOSligand, expressed on human endothelial cells, costimulates Th1 and Th2 cytokine secretion by memory CD4+ T cells. Proc Natl Acad Sci U S A 99: 6198-6203.

13. Manes TD, Pober JS (2008) Antigen presentation by human microvascular endothelial cells triggers ICAM-1-dependent transendothelial protrusion by, and fractalkine-dependent transendothelial migration of, effector memory CD4+ T cells. J Immunol 180: 8386-8392.
CM [46]. The data presented here, in combination with our recent demonstration that $\mathrm{HBEC}$ can transfer antigens from malarial-infected red blood cells onto their surface, thereby becoming a target for the immune response, provide key evidence for HBEC to act as antigen presenting cells with the presentation of malaria antigens by brain EC to $\mathrm{T}$ cells and the potential activation of cytotoxic mechanisms providing a new explanation for CM pathogenesis.

\section{Supporting Information}

Figure S1 Separation of HBEG and PBMC results in a reduction in both $\mathrm{CD}^{+}$and $\mathrm{CD}^{+} \mathrm{T}$ cell proliferation. Graphical representation of fold increase in proliferation of $\alpha \mathrm{CD} 3 / \mathrm{CD} 28$ stimulated $\mathrm{CD}^{+}$and $\mathrm{CD}^{+} \mathrm{T}$ cells co-cultured with TNF/IFN $\gamma$ stimulated HBEC over unstimulated (control) $\mathrm{CD}^{+}$and $\mathrm{CD}^{+} \mathrm{T}$ cell proliferation. Proliferation assessed by CFSE following 6 days of co-culture either in 24 well plates (black bars) or in $0.4 \mu \mathrm{m}$ transwells (white bars).

(TIF)

\section{Acknowledgments}

We thank Gerard Chan for his technical assistance.

\section{Author Contributions}

Conceived and designed the experiments: JW VG GG. Performed the experiments: JW SO. Analyzed the data: JW SO. Contributed reagents/ materials/analysis tools: PC. Wrote the paper: JW VC GG.

14. Perez VL, Henault L, Lichtman AH (1998) Endothelial antigen presentation: stimulation of previously activated but not naive TCR-transgenic mouse T cells. Cell Immunol 189: 31-40.

15. Murray AG, Libby P, Pober JS (1995) Human vascular smooth muscle cells poorly co-stimulate and actively inhibit allogeneic CD4+ T cell proliferation in vitro. J Immunol 154: 151-161.

16. Biedermann BC, Pober JS (1999) Human vascular endothelial cells favor clonal expansion of unusual alloreactive CTL. J Immunol 162: 7022-7030.

17. Lichtman A (2007) Endothelial antigen presentation. In: WC A, editor. Endothelial Biomedicine. New York: Cambridge University Press. pp. 10981107.

18. Weksler BB, Subileau EA, Perriere N, Charneau P, Holloway K, et al. (2005) Blood-brain barrier-specific properties of a human adult brain endothelial cell line. FASEB J 19: 1872-1874.

19. Coureuil M, Lecuyer H, Scott MG, Boularan C, Enslen H, et al. (2010) Meningococcus Hijacks a beta2-adrenoceptor/beta-Arrestin pathway to cross brain microvasculature endothelium. Cell 143: 1149-1160.

20. Coureuil M, Mikaty G, Miller F, Lecuyer H, Bernard C, et al. (2009) Meningococcal type IV pili recruit the polarity complex to cross the brain endothelium. Science 325: 83-87.

21. Pober JS (1999) Immunobiology of human vascular endothelium. Immunol Res 19: 225-232.

22. Turner RR, Beckstead JH, Warnke RA, Wood GS (1987) Endothelial cell phenotypic diversity. In situ demonstration of immunologic and enzymatic heterogeneity that correlates with specific morphologic subtypes. Am J Clin Pathol 87: 569-575.

23. Omari KM, Dorovini-Zis K (2003) CD40 expressed by human brain endothelial cells regulates CD4+ T cell adhesion to endothelium. J Neuroimmunol 134: $166-178$.

24. Schonbeck U, Libby P (2001) The CD40/CD154 receptor/ligand dyad. Cell Mol Life Sci 58: 4-43.

25. Yoshinaga SK, Whoriskey JS, Khare SD, Sarmiento U, Guo J, et al. (1999) Tcell co-stimulation through B7RP-1 and ICOS. Nature 402: 827-832.

26. Klingenberg R, Autschbach F, Gleissner C, Giese T, Wambsganss N, et al. (2005) Endothelial inducible costimulator ligand expression is increased during human cardiac allograft rejection and regulates endothelial cell-dependent alloactivation of CD8+ T cells in vitro. Eur J Immunol 35: 1712-1721.

27. Reynolds DJ, Pearce JH (1990) Characterization of the cytochalasin D-resistant (pinocytic) mechanisms of endocytosis utilized by chlamydiae. Infect Immun 58: 3208-3216. 
28. Hauss P, Selz F, Cavazzana-Calvo M, Fischer A (1995) Characteristics of antigen-independent and antigen-dependent interaction of dendritic cells with CD4+ T cells. Eur J Immunol 25: 2285-2294.

29. Trickett A, Kwan YL (2003) T cell stimulation and expansion using anti-CD3/ CD28 beads. J Immunol Methods 275: 251-255.

30. Lohse AW, Knolle PA, Bilo K, Uhrig A, Waldmann C, et al. (1996) Antigenpresenting function and B7 expression of murine sinusoidal endothelial cells and Kupffer cells. Gastroenterology 110: 1175-1181.

31. Knolle PA, Uhrig A, Hegenbarth S, Loser E, Schmitt E, et al. (1998) IL-10 down-regulates $\mathrm{T}$ cell activation by antigen-presenting liver sinusoidal endothelial cells through decreased antigen uptake via the mannose receptor and lowered surface expression of accessory molecules. Clin Exp Immunol 114: 427-433.

32. Limmer A, Ohl J, Kurts C, Ljunggren HG, Reiss Y, et al. (2000) Efficient presentation of exogenous antigen by liver endothelial cells to CD8+ T cells results in antigen-specific T-cell tolerance. Nat Med 6: 1348-1354.

33. Sherman LA, Chattopadhyay S (1993) The molecular basis of allorecognition. Annu Rev Immunol 11: 385-402.

34. Rodig N, Ryan T, Allen JA, Pang H, Grabie N, et al. (2003) Endothelial expression of PD-L1 and PD-L2 down-regulates CD8+ T cell activation and cytolysis. Eur J Immunol 33: 3117-3126.

35. Monso-Hinard C, Lou JN, Behr C, Juillard P, Grau GE (1997) Expression of major histocompatibility complex antigens on mouse brain microvascular endothelial cells in relation to susceptibility to cerebral malaria. Immunology 92: 53-59.

36. Hirayasu K, Ohashi J, Kashiwase K, Hananantachai H, Naka I, et al. (2012) Significant association of KIR2DL3-HLA-C1 combination with cerebral malaria and implications for co-evolution of KIR and HLA. PLoS Pathog 8: e1002565.

37. Cohen JN, Guidi CJ, Tewalt EF, Qiao H, Rouhani SJ, et al. (2010) Lymph node-resident lymphatic endothelial cells mediate peripheral tolerance via Aireindependent direct antigen presentation. J Exp Med 207: 681-688.
38. Bourdoulous S, Beraud E, Le Page C, Zamora A, Ferry A, et al. (1995) Anergy induction in encephalitogenic $\mathrm{T}$ cells by brain microvessel endothelial cells is inhibited by interleukin-1. Eur J Immunol 25: 1176-1183.

39. Alvarez JI, Krishnamurthy J, Teale JM (2009) Doxycycline treatment decreases morbidity and mortality of murine neurocysticercosis: evidence for reduction of apoptosis and matrix metalloproteinase activity. Am J Pathol 175: 685-695.

40. Wang X, Michie SA, Xu B, Suzuki Y (2007) Importance of IFN-gammamediated expression of endothelial VCAM-1 on recruitment of CD8+ T cells into the brain during chronic infection with Toxoplasma gondii. J Interferon Cytokine Res 27: 329-338.

41. Schofield L, Grau GE (2005) Immunological processes in malaria pathogenesis. Nat Rev Immunol 5: 722-735.

42. Chizzolini C, Grau GE, Geinoz A, Schrijvers D (1990) T lymphocyte interferongamma production induced by Plasmodium falciparum antigen is high in recently infected non-immune and low in immune subjects. Clin Exp Immunol 79: 95-99.

43. Grau GE, Piguet PF, Engers HD, Louis JA, Vassalli P, et al. (1986) L3T4+ T lymphocytes play a major role in the pathogenesis of murine cerebral malaria. J Immunol 137: 2348-2354.

44. Belnoue E, Kayibanda M, Vigario AM, Deschemin JC, van Rooijen N, et al. (2002) On the pathogenic role of brain-sequestered alphabeta CD8+ T cells in experimental cerebral malaria. J Immunol 169: 6369-6375.

45. Lou J, Dayer JM, Grau GE, Burger D (1996) Direct cell/cell contact with stimulated $\mathrm{T}$ lymphocytes induces the expression of cell adhesion molecules and cytokines by human brain microvascular endothelial cells. Eur J Immunol 26: 3107-3113.

46. Combes V, Taylor TE, Juhan-Vague I, Mege JL, Mwenechanya J, et al. (2004) Circulating endothelial microparticles in malawian children with severe falciparum malaria complicated with coma. JAMA 291: 2542-2544. 